\title{
An Empirical Study on the Service Quality of Postgraduate Teaching
}

\author{
Yanliang Zhang, Yuanyuan Xu, Junya Li \\ School of Management Engineering, Zhengzhou University, Zhengzhou 450001, China
}

1483090882@qq.com

Keywords: Service quality of teaching, Management science and engineering, KANO model, SERVQUAL model

\begin{abstract}
The evaluation of postgraduate teaching service quality is an important part of the control of graduate teaching. In this paper, the KANO model and SERVQUAL are used to diagnose and evaluate the teaching quality of management science and engineering graduate. Through the questionnaire, data processing and analysis, it is found that the satisfaction degree of the teaching quality of management science and engineering graduate is negative, which shows that students of management science and engineering are not satisfied with the teaching service provided by their schools. It means that there is a large room for them to improve. Students are more sensitive to the services provided by the teacher and pay more attention to open and fair competition. Based on the empirical analysis results, suggestions for improvement are proposed.
\end{abstract}

\section{INTRODUCTION}

The evaluation of the quality of postgraduate teaching services is an important part of graduate teaching management, but also an important part of the school to control the quality of graduate teaching. At home and abroad, many scholars have studied the quality of graduate teaching: Li Hongjun and others (Li Hongjun,2016) have studied the impact of the implementation of the "six major projects" on the quality of Graduate Education; ZHANG Bei, WEN Xiao-wei (WEN Xiao-wei,2014) Based on the structural equation model as an research tool, this paper makes an empirical analysis of the postgraduates' educational satisfaction in six research universities in South China; GUO Jie, ZHU Hong-bin (GUO Jie,2016) A KANO model was used to investigate the satisfaction degree of full-time master's degree education; Yu Tianzuo, Han Yingxiong (Yu Tianzuo,2013) Taking SERVQUAL model as an instrument to carry on the empirical research to the service quality management of postgraduate education;Kuo, NT, Chang, KC and others(Kuo,NT,2011) use the KANO model and the importance performance analysis (IPA) model to identify the service quality of tourism and hotel management higher education; Toni Lupo (Toni Lupo,2013) uses the fuzzy SERVQUAL model to measure the reliability of educational quality in the field of higher education in Italy; In conclusion, the methods of evaluation of teaching service quality include SERVQUAL model, customer satisfaction index (CSI) model, KANO model, Importance-Performance model and so on. In comparison, in the evaluation of the quality of education services, SERVQUAL model and KANO model because of logical clarity, easy to use and more academic favored.

Management science and engineering is based on the theory of systems and systems engineering as the main research tools, research management system and the general rules of economic systems and special performance of the cross, the integration of disciplines, domestic and foreign research on the quality of such graduate teaching less. In this paper, KANO model and SERVQUAL scale combined with the management of science and engineering graduate students as an example to study the quality of their teaching in order to find the problems in the teaching process of graduate students. And accordingly, put forward the corresponding improvement measures. 


\section{KANO MODEL AND SERVQUAL MODEL}

\subsection{KANO Model}

Noriaki Kano and his colleague Furnio Takahashi were inspired by the two-factor theory to propose a two-dimensional model of satisfaction and constructed the KANO model. The KANO model (Kano N,1984) divides the different elements of the product or service into five types: demand, one-dimensional demand, glamor demand, insignificant demand, and reverse demand. The purpose of this model is to classify the different needs of customers and identify the vital factors that make customer satisfaction (KurtMatzler,1998). Based on the valid questionnaires, combined with KANO The classification table is shown in Table 1, with the dominant classification category as the element KANO classification. Kano has developed a two- dimensional model to understand customer requirements and their impact on customer satisfaction. The Kano model divides customer requirements into six categories, each of which affects customer satisfaction in a different way. Kano categories are briefly explained as follows:

Attractive (A): The functional presence of these attributes will result high level of CS while their absence will not affect CS.

One-dimensional $(\mathrm{O})$ : The functional presence of these attributes will generate CS while their absence will results in non-satisfaction. Must-be (M): Customers take the presence of these attributes for granted. Insufficiency of these attributes will results in extreme non-satisfaction, but the sufficiency will not increase satisfaction

Level. Indifferent (I): The attributes in this category, whether present or not, does not affect CS. Reverse (R): The presence of these attributes will generate non- satisfaction, and vice versa. Questionable (Q): This outcome indicates that either the responses do not make any logical sense, or the question was phrased incorrectly.

Table 1: Kano evaluation table

\begin{tabular}{|c|c|c|c|c|c|c|}
\hline \multicolumn{2}{|c|}{$\begin{array}{c}\text { Service } \\
\text { characteristics }\end{array}$} & \multicolumn{5}{c|}{ Dysfunctional } \\
\hline \multirow{4}{*}{$\begin{array}{c}\text { Functiona } \\
\text { I }\end{array}$} & Table & Like & Must-be & $\begin{array}{c}\text { Neutra } \\
\text { l }\end{array}$ & Live-with & Dislike \\
\cline { 2 - 7 } & Like & Q & A & A & A & O \\
\cline { 2 - 7 } & Must-be & R & I & I & I & M \\
\cline { 2 - 8 } & Neutral & R & I & I & I & M \\
\cline { 2 - 8 } & $\begin{array}{c}\text { Live-wit } \\
\text { h }\end{array}$ & R & I & I & I & M \\
\cline { 2 - 8 } & Dislike & R & R & R & R & Q \\
\hline
\end{tabular}

As shown in table 1, the Kano model use functional and dysfunctional questionnaires, and 5 by 5 evaluation table as conducting instrument.

\subsection{Service Quality Model}

SERVQUAL is a tool to assess the perceptions and expectations based customer service quality questionnaire, its core is the "gap model of service quality, service quality depends on the degree of difference between the user perception and expectation. The model is: SERVQUAL score is the difference between perceived fraction and expected fraction. The higher the SERVQUAL score, the greater the difference between customer perception and expectation, and vice versa. The respondents filled out questionnaires according to their actual situation. The SERVQUAL scores were calculated according to the valid questionnaires collected.

\subsection{Research on the Integration of KANO Model and SERVQUAL Model}

KANO model is mainly used in the identification of quality attributes, is a qualitative importance analysis method, focusing on prior control, SERVQUAL widely used in the service industry, to understand the target customer service needs and perception, is a quantitative management and Measure the quality of service analysis methods, focusing on things in control. KANO model can 
only be used for the classification of quality attributes and indicators of the degree of sensitivity of the calculation, but cannot determine whether the service to achieve customer satisfaction. SERVQUAL scale is mainly used to determine the customer's perception and expectations of the gap, but cannot determine the classification and importance of the indicators. The combination of the two can effectively learn from each other, both the quality of the classification of attributes can also determine the indicators of perception and expectations gap. In this paper, the KANO model was used to classify and determine the importance scores and sensitivity. According to the classification results of KANO model, the unrelated factors and adverse quality factors were removed. The residual index was selected as the SERVQUAL scale and then determined by the SERVQUAL scale According to the classification results of KANO model, the importance score, the sensitivity and the satisfaction value of SERVQUAL scale, the problems in the teaching process of management science and engineering graduate students were found in the course of management science and engineering graduate teaching. Put forward the corresponding measures.

\section{EMPRIRICAL RESEARCH}

\subsection{Investigation Based on KANO Model}

\subsubsection{Questionnaire Design of KANO Model}

The KANO questionnaire consists of two parts: the first part is the basic personal information of respondents, including the respondents' gender, home address, admission methods, and the current grade; The second part is on the selected indicators of the KANO questionnaire. Through literature collection, group discussion and mentor guidance, this paper selected 27 indicators, which were divided into five categories.

The first class is the teacher team, including the indicators are: the number of teachers sufficient; professional teachers rich knowledge; teaching lessons to mobilize students enthusiasm; mentor to help students solve learning problems; mentor for students to participate in research opportunities; Provide guidance on employment; mentor teaching in accordance with their aptitude.

The second category is the curriculum, including the indicators are: professional courses set the frontier; professional courses set the system; elective courses of diverse types; curriculum is difficult to moderate; curriculum set reference to social needs.

The third category is the infrastructure, including the indicators are: teaching facilities to meet the needs of students; graduate space is abundant; Institute of complete facilities; library rich resources; library resources to facilitate access.

The fourth category is student management, including the indicators are; school departments work efficiency is high; schools for students to reflect the problems in a timely manner; schools to provide psychological counseling services and guidance; counselors concerned about student learning and life.

The fifth category is recreational activities, including the index: academic lecture novel; professional association academic forum theme; academic exchanges with domestic and foreign scholars in universities; academic activities were moderate; sports and entertainment activities meet the needs of students; open and fair competition.

\subsubsection{Questionnaire Collection on KANO Model}

The survey lasted two weeks and received 60 paper-based questionnaires and 75 web questionnaires. After screening, 55 questionnaires and 58 questionnaires were identified as valid questionnaires. Of which 46 boys, 67 girls, through the national entrance examination students 104 people, through the recommended exemption of students 9 students accounted for 49 students in the first grade, graduate students in the second grade 34 , graduate third grade 30 people.

\subsubsection{Analysis of KANO Model Reliability}

In this paper, the reliability of Cronbach's $\alpha$ coefficient was used as the reliability index of the test scale. The higher the Cronbach's alpha coefficient obtained by this method, the higher the 
reliability of the results of the indicators in the questionnaire, and vice versa. The reliability value of the total scale is 0.932 , the reliability value of the forward problem is 0.931 , the reliability value of the reverse problem is 0.972 , the reliability value of the faculty is 0.764 , the letter of the course is set The value of 0.752 , the reliability of the infrastructure value of 0.818 , student management reliability value of 0.707 , entertainment activity reliability value of 0.721 . After the reliability analysis, we can see that the reliability coefficient of the questionnaire is greater than 0.7 , the overall design of the questionnaire is better, the results of this survey is credible.

\subsubsection{KANO Classification of Each Indicator}

According to the Kano classification table, the KANO classification of the service elements is determined by the maximum percentage of the taxonomy. After the data collection and processing, the indicators of the KANO classification as shown in Table 2.

Table 2 analysis of data

\begin{tabular}{|c|c|c|c|c|c|c|c|c|c|c|c|}
\hline Num & M & O & R & I & Q & A & Attrib & SI & DSI & Impor & Sensit \\
\hline 1 & 53 & 24 & 1 & 17 & 1 & 17 & M & 0.37 & -0.69 & 2.96 & low \\
\hline 2 & 46 & 33 & 1 & 18 & 1 & 14 & M & 0.42 & -0.71 & 2.91 & low \\
\hline 3 & 10 & 22 & 0 & 23 & 1 & 57 & A & 0.71 & -0.29 & 2.15 & high \\
\hline 4 & 17 & 28 & 0 & 14 & 1 & 53 & A & 0.72 & -0.40 & 2.41 & high \\
\hline 5 & 9 & 23 & 1 & 20 & 1 & 59 & A & 0.74 & -0.29 & 2.15 & high \\
\hline 6 & 5 & 29 & 1 & 16 & 1 & 61 & A & 0.81 & -0.31 & 2.17 & high \\
\hline 7 & 12 & 30 & 2 & 19 & 2 & 48 & A & 0.72 & -0.39 & 2.24 & high \\
\hline 8 & 38 & 27 & 1 & 18 & 3 & 26 & M & 0.49 & -0.60 & 2.68 & high \\
\hline 9 & 43 & 28 & 0 & 22 & 3 & 17 & M & 0.41 & -0.65 & 2.76 & high \\
\hline 10 & 23 & 16 & 2 & 31 & 3 & 38 & A & 0.50 & -0.36 & 2.19 & high \\
\hline 11 & 27 & 20 & 0 & 35 & 3 & 28 & I & 0.44 & -0.43 & 2.29 & high \\
\hline 12 & 26 & 28 & 0 & 22 & 2 & 35 & A & 0.57 & -0.49 & 2.48 & high \\
\hline 13 & 51 & 21 & 1 & 19 & 2 & 19 & M & 0.36 & -0.65 & 2.87 & low \\
\hline 14 & 44 & 29 & 1 & 17 & 2 & 20 & M & 0.45 & -0.66 & 2.83 & low \\
\hline 15 & 46 & 30 & 0 & 14 & 3 & 20 & M & 0.45 & -0.69 & 2.90 & low \\
\hline 16 & 41 & 34 & 0 & 18 & 3 & 17 & M & 0.46 & -0.68 & 2.81 & low \\
\hline 17 & 34 & 41 & 0 & 18 & 3 & 17 & O & 0.53 & -0.68 & 2.75 & high \\
\hline 18 & 34 & 39 & 0 & 11 & 2 & 27 & O & 0.59 & -0.66 & 2.81 & high \\
\hline 19 & 28 & 37 & 0 & 14 & 2 & 32 & O & 0.62 & -0.59 & 2.66 & high \\
\hline 20 & 15 & 13 & 0 & 44 & 2 & 39 & I & 0.47 & -0.25 & 1.96 & high \\
\hline 21 & 13 & 14 & 0 & 44 & 2 & 40 & I & 0.49 & -0.24 & 1.93 & high \\
\hline 22 & 14 & 30 & 0 & 25 & 2 & 42 & A & 0.65 & -0.40 & 2.26 & high \\
\hline 23 & 14 & 19 & 0 & 43 & 2 & 35 & I & 0.49 & -0.30 & 2.00 & high \\
\hline 24 & 6 & 15 & 1 & 28 & 3 & 60 & A & 0.69 & -0.19 & 1.92 & high \\
\hline 25 & 9 & 22 & 0 & 35 & 3 & 44 & A & 0.60 & -0.28 & 1.99 & high \\
\hline 26 & 8 & 12 & 0 & 39 & 3 & 51 & A & 0.57 & -0.18 & 1.85 & high \\
\hline 27 & 55 & 25 & 0 & 19 & 2 & 12 & M & 0.33 & -0.72 & 2.99 & low \\
\hline
\end{tabular}

\subsubsection{Determine the Importance of Indicators}

According to the conclusion of Matzer et al., The order of importance of KANO classification is $\mathrm{M}>\mathrm{O}>\mathrm{A}>\mathrm{I}$, which is 4,3,2,1 according to the importance of indicators. The calculation formula of the importance of the index is: $I P_{i}=\left(K 1 * N_{M i}+K 2 * N_{O i}+K 3 * N_{A i}+K 4 * N_{I i}\right) /$

$$
\left(N_{M i}+N_{O i}+N_{A i}+N_{I i}+N_{R i}+N_{Q i}\right)
$$

Among them, the importance score of the i-th index index is $I P_{i}$, the assignment of the index 
KANO classification $K 1=4, K 2=3, K 3=2, K 4=1$. By calculation, the score of importance is shown in table 2.

\subsubsection{Determine the Sensitivity of the Indicator}

The satisfaction index ( $S I$ ) and the dissatisfied influence ( ${ }^{D S I}$ ) index of the influencing factors are calculated according to the following formula.

$$
\begin{aligned}
& S I_{i}=\left(N_{A i}+N_{o i}\right) /\left(N_{A i}+N_{o i}+N_{M i}+N_{I i}\right) \\
& D S I_{i}=-1 *\left(N_{O i}+N_{M i}\right) /\left(N_{A i}+N_{O i}+N_{M i}+N_{I i}\right) \text { The sensitivity of each index was determined }
\end{aligned}
$$

according to $S I$ and $D S I$. The results of the statistical analysis are shown in table 2.

\subsection{Investigation and Research on SERVQUAL Scale}

\subsubsection{Design and Collection of SERVQUAL Scale Questionnaire}

According to the results of the KANO model analysis, the indicators 11,20,21,23 belong to the unrelated factors, that students think that these indicators have no effect on the quality of teaching, followed by the design of SERVQUAL questionnaire, remove the remaining factors, keep the remaining 23 indicators as SERVQUAL model Of the research object.

The questionnaire includes three parts: the first part is the basic personal information of respondents, including their gender, home address, school, the current grade; second part is the respondents to provide teaching service expectations of the school; the third part is to provide teaching services to the school respondents perceived. The two parts of perception and expectation are exactly the same, each of which has 23 items.

The survey lasted two weeks and received 70 paper-based questionnaires and 75 web questionnaires. After screening, 62 paper questionnaires and 50 network questionnaires were selected as valid questionnaires. There were 48 boys and 64 girls, through the national examination enrollment of 101 students, through the recommendation of entrance students 11 people, 49 people of the first grade and the second grade graduate students 35 people, 29 people graduate students in the third grade.

\subsubsection{Scale Structure Analysis}

In this paper, SPSS statistical analysis software was used to analyze the collected data, and exploratory factor analysis was used to explore the scale structure. Before factor analysis, it is determined whether the selected variable is suitable for factor analysis by calculating the $K M O$ value and performing the Butler spherical test. Data analysis showed that the approximate chi square value of $K M O=0.816$, Butler sphere test was $=1359.437(P<0.001)$, which indicated that the survey data was suitable for factor analysis. The purpose of factor analysis was to examine the construct validity of the questionnaire ${ }^{[4]}$. Then, the principal component analysis method is used to analyze the survey data by using the normalized orthogonal rotation method, and the effective number of the extracted factors with the eigenvalue greater than 1 is the extraction criterion. According to the factor analysis results, remove the factor on a factor factor of less than 0.4, and remove the load on both factors with loads greater than 0.4 . This study through the factor analysis, the original five factors expanded to six, as shown in Table 3. 
Table 3 Analysis on the Elements of Educational Service Quality

\begin{tabular}{|c|c|c|c|c|c|c|}
\hline \multirow{2}{*}{ Number } & \multicolumn{5}{|c|}{ Factor of extraction (Orthogonal rotation) } \\
\hline & Factor one & Factor & Factor & Factor & Factor & Factor \\
\hline 15 & 0.703 & & & & & \\
\hline 16 & 0.517 & & & & & \\
\hline 17 & 0.820 & & & & & \\
\hline 6 & 0.753 & & & & & \\
\hline 7 & 0.836 & & & & & \\
\hline 8 & & 0.675 & & & & \\
\hline 9 & & 0.570 & & & & \\
\hline 10 & & 0.701 & & & & \\
\hline 13 & & 0.507 & & & & \\
\hline 22 & & 0.423 & & & & \\
\hline 24 & & 0.820 & & & & \\
\hline 26 & & 0.684 & & & & \\
\hline 1 & & & 0.727 & & & \\
\hline 2 & & & 0.853 & & & \\
\hline 12 & & & 0.530 & & & \\
\hline 19 & & & & 0.794 & & \\
\hline 25 & & & & 0.686 & & \\
\hline 27 & & & & 0.738 & & \\
\hline 16 & & & & & 0.792 & \\
\hline 17 & & & & & 0.830 & \\
\hline 14 & & & & & & 0.463 \\
\hline 15 & 34.337 & 10.865 & 8.579 & 6.159 & 5.173 & 4.480 \\
\hline 18 & & 45.201 & 53.781 & 59.940 & 65.113 & 69.593 \\
\hline Exgenvalues & & 0.852 & 0.766 & 0.713 & 0.706 & 0.712 \\
\hline Cumulative explanation of & 34.337 & & & & & \\
\hline Reliability & & & & & & \\
\hline & & & & & & \\
\hline
\end{tabular}

Combined with factor analysis, the six factors were renamed, respectively, teacher counseling, teaching training, teaching resources, school management, library services, research institute. The expanded six factors cover all the contents of the former five factors, and then subdivide them on the basis of the original, and the structure validity of the questionnaire is more excellent. The reliability of the six factors was above 0.7 , and the reliability was good.

\subsubsection{Reliability Analysis of Scale}

The Cronbach alpha coefficient is the most commonly used reliability coefficient and is an intrinsic consistency coefficient. This study is about the management of science and engineering graduate students satisfaction survey, suitable for the use of the Cronbacha $\alpha$ coefficient for reliability analysis. The number of subjects in this study is 23 , after analysis can be Cronbach alpha coefficient 0.909, the reliability is very good. After SPSS statistical analysis, obtained as shown in Table 3, from the table can be seen in the sub-table reliability are above 0.7 , indicating that each factor has a very good internal consistency. Factor One to Factor VI explains the variance decreases in turn.

\subsubsection{Perceived Expectation Gap}

Based on the basic principles of SERVQUAL, the gap between teaching quality of management science and engineering graduate students is shown in table 4. In addition, the sample T test was conducted on the mean and perceived averages to find out whether there was a statistically significant difference in the quality of service gap. According to the analysis, the academic content 
of the lectures is novel, and the academic value of the academic lectures is more than 0.001 , and the $\mathrm{T}$ values of the other items are significantly different $(\mathrm{P}<0.001)$. , Management science and engineering graduate students on the perception and expectations of teaching services in the 99.9\% confidence level there is a significant difference. Therefore, school administrators should take appropriate measures to bridge the gap.

Table 4 Gap analysis

\begin{tabular}{|c|c|c|c|c|c|}
\hline NUMBER & Expected average & Perceived mean & Gap value & T value & Significance \\
\hline 1 & 4.76 & 3.71 & 1.05 & 15.73 & 0.000 \\
\hline 2 & 4.86 & 3.83 & 1.02 & 13.54 & 0.000 \\
\hline 3 & 4.29 & 3.07 & 1.22 & 9.85 & 0.000 \\
\hline 4 & 4.04 & 3.12 & 0.91 & 9.00 & 0.000 \\
\hline 5 & 4.07 & 3.24 & 0.83 & 14.61 & 0.000 \\
\hline 6 & 4.18 & 2.76 & 1.41 & 14.74 & 0.000 \\
\hline 7 & 4.18 & 2.74 & 1.44 & 14.04 & 0.000 \\
\hline 8 & 4.68 & 3.55 & 1.13 & 12.82 & 0.000 \\
\hline 9 & 4.62 & 3.61 & 1.00 & 5.42 & 0.000 \\
\hline 10 & 4.54 & 3.00 & 1.54 & 17.59 & 0.000 \\
\hline 12 & 4.51 & 3.58 & 0.92 & 10.94 & 0.000 \\
\hline 13 & 4.58 & 3.21 & 1.36 & 11.82 & 0.000 \\
\hline 14 & 4.55 & 3.33 & 1.21 & 12.21 & 0.000 \\
\hline 15 & 4.60 & 3.78 & 0.82 & 11.23 & 0.000 \\
\hline 16 & 4.56 & 3.75 & 0.81 & 10.32 & 0.000 \\
\hline 17 & 4.01 & 3.15 & 0.86 & 10.52 & 0.000 \\
\hline 18 & 3.97 & 3.16 & 0.80 & 12.16 & 0.000 \\
\hline 19 & 4.00 & 3.28 & 0.72 & 8.23 & 0.000 \\
\hline 22 & 3.67 & 3.36 & 0.31 & 2.73 & 0.007 \\
\hline 24 & 3.80 & 3.25 & 0.55 & 3.49 & 0.001 \\
\hline 25 & 3.71 & 3.35 & 0.35 & 1.14 & 0.255 \\
\hline 26 & 3.64 & 3.51 & 0.12 & 11.88 & 0.000 \\
\hline
\end{tabular}

\subsection{MODEL ANALYSIS RESULTS}

According to the model empirical analysis results can be seen:The importance of high scores of the competition open and impartial, the number of teachers, the amount of teachers in specialized courses, the Institute of the situation, teaching facilities to meet student needs, the status of the library, the various departments of the school efficiency, professional curriculum set the frontier system, Timely to solve the problem of students to reflect; Highly instructive teachers can improve the enthusiasm of the students, the mentor to help students solve the problem of learning, the mentor for students to participate in the study of the opportunity to provide guidance for students to provide guidance; In the gap model, there are abundant elective courses in the gap model, and the instructor is instructed to provide students with employment guidance. The teaching facilities meet the needs of the students and the enthusiasm of the instructors to mobilize the students. The Institute has sufficient space. Sexual system, the number of teachers and so on.

\section{CONCLUSIONS AND SUGGESTIONS}

From the model analysis results, the following conclusions can be drawn: First: the use of KANO model classification of the indicators, belonging to the same category between the importance of the indicators can not be known. The importance and sensitivity of the indicators in the same category can be judged by the importance score and the sensitivity, making the solution 
more scientific and reasonable. Second, the KANO model is a method of importance analysis for quality attribute identification, focusing on prior control. The SERVQUAL scale is an analytical method used to understand the customer's expectations and perceived quantitative management and measurement of service quality. The combination of the two, you can learn from each other, so that the investigation is more accurate and credible. Third, the management science and engineering graduate students on the quality of teaching satisfaction analysis data are negative, indicating that the management of science and engineering graduate teaching services can not meet the needs of students, the school has a lot of room for improvement.

Based on the above findings, the following recommendations were made: Combined with the KANO model to achieve the quality of the results of identification: First, the energy should be spent to improve the quality of essential, in the process of improving the quality of the importance of the importance of the size of the score, the level of sensitivity, quality of service to consider the gap , The first to improve the quality of the necessary quality of service gaps, high sensitivity, the importance of large scores. Second, to improve the quality of a dollar in the quality of service gap, high sensitivity, the importance of large scores. Again, if the school wants to significantly improve customer satisfaction, you can consider improving the quality of the elements of charm, because the improvement of the quality of charm elements will greatly improve customer satisfaction. The indiscriminate quality factor has no significant effect on student satisfaction, and no need to consider indiscriminate quality. In the limited resources under the conditions of the school, the school should first in the teaching facilities, research institutes, professional courses set the frontier system and teachers to increase investment. Second, the library resources to obtain, the school to improve. Moreover, if the school wants to continue to improve student satisfaction, teachers can improve the requirements, such as the rich content of teachers to enrich the diversity of forms to fully mobilize the enthusiasm of students to learn; mentor to participate in the study of students to provide opportunities and employment guidance, to attach importance to teaching students according to their aptitude.

\section{ACKNOWLEDGEMENTS}

This research is supported by 2017 Postgraduate Education Research project of Zhengzhou University to Yanliang Zhang.

\section{REFERENCES}

[1] Bei Zhang, Xiaowei Wen., 2014. An Empirical Research on Graduate Satisfaction in Research Universities Based in the Example of 6 Research Universities in South China [J]. China Higher Education Research, (2):64-69.

[2] Hongjun Li., 2016. On Implementation of “Six Projects” for Comprehensive Improvement of Quality of Graduate Education [J]. Journal of Southwest China Normal University (Natural Science), (06): 208-212.

[3] JieGuo, Hongbin Zhang., 2015. Research on Education Satisfaction of Full-time Professional Master Based on Kano Mddel--Taking L University for an Example., (8):88-93.

[4] Kano N, Seraku F, Tsuji S.,1984. Attractive Quality and Must-Be Quality[J].Hintshitsu, 14(2);56-147.

[5] KurtMatzler, Hans H.Hinterhuber.,1998. How to make product development projects more successful by intergrating model of customer satisfaction into quality function deployment [J].Technovation,18(1);25-38.

[6] Kuo,NT, Chang,KC, Lai,CH.,2011. Identifying critical service quality attributes for higher education in hospitality and tourism: Applications of the Kano model and importance- performance analysis (IPA)[J]. AFRICAN JOURNAL OF BUSINESS MANAGEMENT, 5(30); 12016- 12024. 
[7] Tianzuo Xu, Yingxiong Han., 2013.A SERVQUAL-based Study of Service Quality Management in Postgraduate Education [J]. Journal of Graduate Education, (1):11-16.

[8] Toni Lupo., 2013.A fuzzy ServQual based method for reliable measurements of education quality in Italian higher education area[J]. Expert Systems with Applications, 17(40); 7096- 7110. 